\title{
Study on Solid Phase Extraction and Electrothermal Atomic Absorption Spectrometry for the Determination of Ultra-trace Cadmium in Seawater Samples With Aliquat-336 Modified Silica Gel
}

\author{
Yingjie Lia ${ }^{\text {** }}$, Guangshun Hou ${ }^{\mathrm{b}}$, Bo Zhou ${ }^{\mathrm{a}}$, and Yunlong Wei ${ }^{\mathrm{a}}$ \\ a Department of Physics and Chemistry, Henan Polytechnic University, \\ Jiaozuo 454003, P.R. China \\ b School of Resources and Environment Engineering, Henan Polytechnic University, \\ Jiaozuo 454003, P.R. China
}

\section{INTRODUCTION}

In recent years, the use of cadmium (Cd) in electroplating, alloys, soft solder, dyestuffs, and in various other industries has become one of the major sources of environmental pollution, including the oceans (1). Cadmium is considered the sixth most poisonous element which accumulates in several organs and has carcinogenic effects. Exposure to lower doses of Cd may cause gastrointestinal irritation, vomiting, abdominal pain, and diarrhea. Acute exposure may affect the kidney functions and result in tubular proteinosis and even death (2). Therefore, the determination of ultra-trace Cd in seawater is of prime importance in order to assess the early impact of human activities on the marine environment.

Several highly sensitive and selective analytical techniques including inductively coupled plasma mass spectrometry (ICP-MS) $(3,4)$, inductively coupled plasma optical emission spectrometry (ICPOES) $(5,6)$, flame atomic absorption spectrometry (FAAS) $(7,8)$, and electrothermal atomic absorption spectrometry (ETAAS) $(9,10)$ have been proposed for the determination of ultra-trace $\mathrm{Cd}$ in natural samples. Since many laboratories do not have ICP-MS and/or ICP-OES instrumentation available, ETAAS is an efficient alternative since it offers excellent detection limits,

\section{ABSTRACT}

A simple and sensitive method for the determination of ultratrace cadmium (Cd) by solid phase extraction (SPE), combined with electrothermal atomic absorption spectrometry (ETAAS), is presented and evaluated. The method based on $\mathrm{Cd}^{2+}$ was complexed with $\mathrm{I}^{-}$to form $\mathrm{CdI}_{4}{ }^{2-}$. The $\mathrm{CdI}_{4}{ }^{2-}$ was quantitatively retained by Aliquat-336 modified silica gel (AMSG) sorbent. This process entailed anion exchange and a positively charged surface, which facilitated favorable retention of the negatively charged ions. The retained Cd(II) was effectively recovered with $2.0 \mathrm{~mol} \mathrm{~L}^{-1} \mathrm{HNO}_{3}$, and quantified by ETAAS.

Under the optimized conditions, the limit of detection (LOD) for Cd(II) was $5.1 \mathrm{ng} \mathrm{L}^{-1}$ using a 30.0-mL sample solution. The relative standard deviation (RSD) for 10 replicate measurements of $100 \mathrm{ng} \mathrm{L}^{-1} \mathrm{Cd}(\mathrm{II})$ was $2.3 \%$.

The developed technique demonstrated its application for the determination of ultra-trace cadmium in seawater samples. The recoveries for the spiked samples were in the 95.6-106.8\% range. In order to validate the developed method, certified reference material GBW(E) 080040 seawater sample was analyzed and the determined values were found to be in good agreement with the certified values. and low instrumental and operating costs (11). Moreover, real samples often consist of complex matrixes which makes it difficult to determine low level Cd concentrations. Thus, an efficient separation and preconcentration method is necessary to eliminate matrix effects as well as to concentrate the analyte.

The most widely used techniques for the separation and preconcentration of ultra-trace cadmium include coprecipitation $(12,13)$, liquid-liquid extraction (LLE) (14), cloud point extraction (CPE) $(6,15)$, and solid-phase extraction (SPE) (16-28). Among these methods, SPE has proved to be the most efficient protocol for the separation and preconcentration of ultra-trace metal species. SPE offers many advantages over other separation/ preconcentration techniques such as higher enrichment, simpler operation, low consumption of organic solvent, time savings, and cost savings.

It should be noted that selection of the adsorption medium plays a key role in the development of SPE. Suitable solid materials for the determination of trace analytes in various samples include activated carbon (16), sulfur (17), modified peanut shell (18), Amberlite XAD1180 (19), $\mathrm{TiO}_{2}$ nanotubes (20), carbon nanotubes (21), and silica gel (22-28).

Among the above-mentioned materials, silica gel as a solid adsorbent is most commonly used because it is non-deforming, has good mechanical strength and heat- 
stability. Chemically modified silica gel is one of the most successful adsorbents because of good thermal stability and appropriate accessibility of ions to the adsorbent groups. In addition, modified silica gel exhibits higher sorption capacities than organic polymer-based resins. Some chelating agents have been modified on silica gel as solid adsorbents for the preconcentration of some metal ions such as anninothioamidoanthraquinone (22), triethylenetetraminomethylenephosphonic acid (23), 2-(2-oxoethyl)hydrazine carbothioamide (24), 4-amino-2-mercaptopyrimidine (25), ethyl-2-benzothiazolylacetate (26), benzoylthiourea (27), and murexide (28).

Aliquat-336 is a kind of cationic surfactant, which was applied to the selective extraction of chromium species (29). The separation of anionic $\mathrm{Cr}(\mathrm{VI})$ was achieved by formation of the hydrophobic ionassociated complex. The head group of the cationic surfactant behaves like a chelating agent, which reacts with the anionic species of $\mathrm{Cr}(\mathrm{VI})$ and, preconcentrated into the surfactant-rich phase, then separates from Cr(III) in the initial solution.

The aim of this work was to develop an SPE method using a microcolumn packed with Aliquat336 modified silica gel (AMSG) and ETAAS detection of ultra-trace cadmium in seawater samples. In the presence of $\mathrm{I}^{-}$, the $\mathrm{Cd}(\mathrm{II})$ retained by the AMSG via electrostatic interaction and anion exchange was readily recovered with $\mathrm{HNO}_{3}$ and quantified with ETAAS. The retention and elution conditions for optimal experimental conditions were established. The developed technique was validated by analyzing certified reference material GBW(E) 080040 Seawater and found to be applicable for the determination of ultra-trace cadmium in real seawater samples.

\section{EXPERIMENTAL}

\section{Instrumentation}

A TAS-990 atomic absorption spectrometer and a standard THGA ${ }^{\mathrm{TM}}$ transversely heated graphite furnace using graphite tubes with an integrated pyrolytically coated platform (Beijing Purkinje General Instrument Co. Ltd., Beijing, P.R. China) were employed. A cadmium hollow cathode lamp (Beijing Shuguangming Electronic Lighting Instrument Co. Ltd., Beijing, P.R. China) was the radiation source. Argon 99.99\% was used as the protective and purge gas. The instrumental operating conditions and the temperature program for ETAAS determination are summarized in Table I. An HL-2 peristaltic pump (Shanghai Qingpu Huxi Instrument Factory, Shanghai, P.R. China) was employed to propel the solution. A conical microcolumn (0.6 mm $\times 5 \mathrm{~mm}, 50 \mathrm{~mm}$ length, $200 \mu \mathrm{L}$ pipet tip, from Yuhua Experimental Instrument Factory, Haimen, Jiangsu, P.R. China) made of polypropylene material was used as the Aliquat-336 modified silica gel sorbent holder. The $\mathrm{pH}$ values were

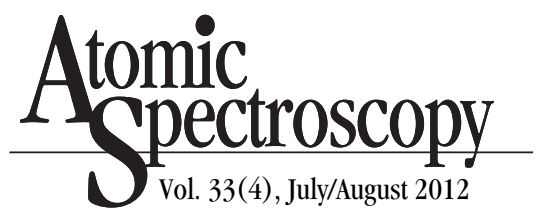

performed with a PHS-3B pH meter (Shanghai Precision \& Scientific Instrument Co. Ltd., P.R. China) supplied with a combined glass electrode.

\section{Standard Solutions and Reagents}

A $1.0 \mathrm{mg} \mathrm{mL}^{-1}$ stock standard solution of $\mathrm{Cd}(\mathrm{II})$ was purchased from the National Analysis Center for Ion and Steel (Beijing, P.R. China). Working standard solutions were obtained by appropriate dilution of the stock standard solution with $2 \%$ hydrochloric acid (v/v) just before use. A $0.2 \mathrm{~mol} \mathrm{~L}^{-1}$ solution of KI (Guangzhou Huaxue ShijiChang, Guangzhou, P.R. China) was prepared by dissolution in deionized doubly distilled water. Methyl trioctyl ammonium chloride (Aliquat336) was obtained from Sinopharm Chemical Reagent Co., Ltd., Shanghai, P.R. China. Stock solutions of the interfering elements $\left(\mathrm{Na}^{+}, \mathrm{K}^{+}\right)$ were prepared from their analytical reagents by dissolving $\mathrm{NaCl}$ and $\mathrm{KCl}$ (Shanghai Reagent Factory, Shanghai, P.R. China) in deionized doubly distilled water. Stock solutions of the interfering elements

TABLE I

ETAAS Operating Conditions and Temperature Program for the Determination of $\mathrm{Cd}$

\begin{tabular}{|c|c|c|c|c|}
\hline \multicolumn{2}{|c|}{ Instrumentation } & \multicolumn{3}{|c|}{ Purkinje General TAS-990 AAS } \\
\hline \multicolumn{2}{|c|}{ Wavelength } & \multicolumn{3}{|c|}{$228.8 \mathrm{~nm}$} \\
\hline \multicolumn{2}{|c|}{ Spectral bandwidth } & \multicolumn{3}{|l|}{$0.4 \mathrm{~nm}$} \\
\hline \multicolumn{2}{|c|}{ Lamp Current } & \multicolumn{3}{|l|}{$2.0 \mathrm{~mA}$} \\
\hline \multicolumn{2}{|c|}{ Background Correction } & \multicolumn{3}{|c|}{ Deuterium } \\
\hline \multicolumn{2}{|c|}{ Sample Volume } & \multicolumn{3}{|l|}{$10 \mu \mathrm{L}$} \\
\hline \multicolumn{2}{|c|}{ Measurement Mode } & \multicolumn{3}{|c|}{ Peak Height } \\
\hline \multicolumn{5}{|c|}{ Graphite Atomizer Temperature Program } \\
\hline Step & $\begin{array}{l}\text { Temperature } \\
\left({ }^{\circ} \mathrm{C}\right)\end{array}$ & $\begin{array}{l}\text { Ramp Time } \\
\text { (s) }\end{array}$ & $\begin{array}{l}\text { Hold Time } \\
\text { (s) }\end{array}$ & $\begin{array}{l}\text { Argon Flow Rate } \\
\left(\mathrm{mL} \mathrm{min}^{-1}\right)\end{array}$ \\
\hline Drying & 100 & 10 & 15 & 450 \\
\hline Ashing & 500 & 10 & 15 & 450 \\
\hline Atomization & 1800 & 0 & 3 & 0 \\
\hline Cleaning & 2100 & 1 & 2 & 450 \\
\hline
\end{tabular}


$\left(\mathrm{Mg}^{2+}, \mathrm{Ca}^{2+}, \mathrm{Zn}^{2+}, \mathrm{Al}^{3+}, \mathrm{Cu}^{2+}, \mathrm{Pb}^{2+}\right.$, and $\mathrm{Fe}^{3+}$ ) were prepared by dissolving certain amounts of their inorganic salts $\left[\mathrm{Mg}\left(\mathrm{NO}_{3}\right)_{2}, \mathrm{CaCl}_{2}, \mathrm{ZnCl}_{2}\right.$, $\mathrm{Al}\left(\mathrm{NO}_{3}\right)_{3}, \mathrm{CuCl}_{2}, \mathrm{~Pb}\left(\mathrm{NO}_{3}\right)_{3}$, and $\mathrm{Fe}\left(\mathrm{NO}_{3}\right)_{3}$ ] (Shanghai Reagent Factory, Shanghai, P.R. China) in 2\% (v/v) HCl. Stock solutions of the interfering anions $\left(\mathrm{Cl}^{-}\right.$and $\left.\mathrm{SO}_{4}{ }^{2-}\right)$ were prepared from their analytical reagents by dissolving certain amounts of $\mathrm{NH}_{4} \mathrm{Cl}$ and $\left(\mathrm{NH}_{4}\right)_{2} \mathrm{SO}_{4}$ (Shanghai Jingchun Industry Co., Ltd., Shanghai, P.R. China) in deionized doubly distilled water. The certified reference material GBW(E) 080040 Seawater was supplied by the Second Institute of Oceanography Institute of China (Hangzhou, P.R. China). The $\mathrm{pH}$ adjustments were performed with $\mathrm{HCl}$ and $\mathrm{NH}_{3} \cdot \mathrm{H}_{2} \mathrm{O}$. All chemicals and reagents used in this study were of analytical reagent grade or higher purity.

Silica gel (100-200 mesh) (Qingdao Haiyang Chemical Co., Ltd., Qingdao, P.R. China) was immersed in ethanol and $1 \mathrm{~mol} \mathrm{~L}^{-1}$ $\mathrm{HNO}_{3}$ for 24 hours, then filtered and washed with deionized doubly distilled water until neutral, and dried prior to storage for future use.

All stock standard solutions were stored in polyethylene bottles in a refrigerator held at $4{ }^{\circ} \mathrm{C}$. Glass containers and all other immersed laboratory materials that could come into contact with the samples or standards were stored in 10\% (v/v) nitric acid, and rinsed with deionized doubly distilled water prior to use.

\section{Preparation of AMSG}

$5.0 \mathrm{~g}$ of the activated silica gel was immersed into $100 \mathrm{~mL}$ deionized doubly distilled water with $1.0 \mathrm{~g}$ of Aliquat-336. The mixture was magnetically stirred for 2 hours and left standing for 4 hours at room temperature. Then, the silica gel was filtered with a $0.45 \mu \mathrm{m}$ membrane filter (Shanghai Xingya Purification Material Factory, Shanghai, P.R. China) and washed with deionized doubly distilled water in order to eliminate the redundant Aliquat-336 on the surface of the adsorbent. The resulting material was dried at room temperature for future use.

\section{Microcolumn Preparation}

A 50-mg amount of AMSG was filled into a $200-\mu \mathrm{L}$ pipet tip plugged with small amounts of cotton at both ends. After cleaning with $2 \mathrm{~mL}$ of deionized doubly distilled water, the microcolumn was conditioned to the desired $\mathrm{pH}$ with an appropriate HAc-NaAc buffer solution.

The microcolumn can be reused after washing with $1.2 \mathrm{~mL}$ of $2.0 \mathrm{~mol} \mathrm{~L}^{-1} \mathrm{HNO}_{3}$ and then rinsing with deionized doubly distilled water to the $\mathrm{pH}$ of about 7.0.

\section{General Procedure}

For solid phase extraction and preconcentration of cadmium ions, aliquots of the sample solutions containing $\mathrm{Cd}$ (II) and $0.01 \mathrm{~mol} \mathrm{~L}^{-1}$ of KI were prepared and the $\mathrm{pH}$ value was adjusted to $\mathrm{pH} 6.0$ with $0.1 \mathrm{~mol} \mathrm{~L}^{-1} \mathrm{HCl}$ and $\mathrm{NH}_{3} \cdot \mathrm{H}_{2} \mathrm{O}$. The solution was passed through the microcolumn by using a peristaltic pump at $4.0 \mathrm{~mL} \mathrm{~min}^{-1}$ of sample flow rate. The analyte retained on the microcolumn was eluted with $1.2 \mathrm{~mL} 2.0 \mathrm{~mol} \mathrm{~L}^{-1}$ of $\mathrm{HNO}_{3}$ at a flow rate of $4.0 \mathrm{~mL} \mathrm{~min}^{-1}$, and the analyte in the eluent was determined by ETAAS.

\section{Sample Preparation}

The seawater samples (Dalian, Beihai, Qingdao and Xiamen, P.R. China) were collected in acidleached polyethylene bottles and filtered with a $0.45 \mu \mathrm{m}$ membrane filter prior to analysis. The waters were acidified with $\mathrm{HCl}$ and stored in a refrigerator at $4^{\circ} \mathrm{C}$. Before performing the SPE procedure, the samples were adjusted to $\mathrm{pH} 6.0$ with $0.1 \mathrm{~mol} \mathrm{~L}^{-1} \mathrm{HCl}$ and $0.1 \mathrm{~mol} \mathrm{~L}^{-1}$ $\mathrm{NH}_{3} \cdot \mathrm{H}_{2} \mathrm{O}$.

\section{RESULTS AND DISCUSSION}

\section{Extraction Mechanism of Cd(II)}

Aliquat-336 is a cationic surfactant, therefore Aliquat-336 modified silica gel material can selectively adsorb negatively charged ions via electrostatic interactions and anionexchange. $\mathrm{Cd}^{2+}$ mainly existed in anionic form in the presence of $\mathrm{I}^{-}$, and thus was quantitatively adsorbed by AMSG. The principle may be expressed in the following reaction equation:

$$
\begin{aligned}
& \mathrm{Cd}^{2+}+4 \mathrm{I}^{-} \rightarrow \mathrm{CdI}_{4}{ }^{2-} \\
& 2\left[\mathrm{R}_{3} \mathrm{R}^{\prime} \mathrm{N}\right]^{+}+\mathrm{CdI}_{4}{ }^{2-} \rightarrow\left[\mathrm{R}_{3} \mathrm{R}^{\prime} \mathrm{N}\right]^{+}{ }_{2}\left(\mathrm{CdI}_{4}\right)^{2-}
\end{aligned}
$$

\section{Atomic Absorption Profile of Cd in ETAAS}

For the sake of clarity, the atomic absorption peaks of cadmium and the blank atomization at $1800{ }^{\circ} \mathrm{C}$ with an SPE step were also studied; the results are shown in Figure 1. As can be seen, under the selected atomization temperature a sharp and strong atomic absorption peak of the analyte (Figure 1a) was obtained. Figure $1 \mathrm{~b}$ is the signal profile of the blank solution and no remarkable blank signal could be detected.

\section{Effect of $\mathbf{p H}$}

The $\mathrm{pH}$ value plays an important role in the SPE procedure. An appropriate $\mathrm{pH}$ value can not only improve the adsorption efficiency, but also depress the interference of the matrix. For this study, the $\mathrm{pH}$ of the sample solutions was adjusted from 1.0 to 7.0 and operated according to the general procedure. Figure 2 shows the effect of $\mathrm{pH}$ on the adsorption of $\mathrm{Cd}^{2+}$ in the microcolumn of the AMSG material. It clearly indicated that $\mathrm{Cd}^{2+}$ was quantitatively absorbed at the whole $\mathrm{pH}$ test range. This observation is apparently attributed to the 
electrostatic interactions and the anion-exchange nature of the AMSG between $\mathrm{Cd}(\mathrm{II})$ and the modified silica gel surface. In the presence of $\mathrm{I}^{-}, \mathrm{Cd}^{2+}$ mainly existed as $\mathrm{CdI}_{4}{ }^{2-}$ anions in the $\mathrm{pH}$ range studied, indicating maximum electrostatic interaction between Cd(II) and the methyl trioctyl ammonium group, which corresponded to a maximum absorbance. On the other hand, the modified silica gel surface is posi- tively charged in the $\mathrm{pH}$ range tested, and at the same time the chlorides on the AMSG are replaced by $\mathrm{CdI}_{4}^{2-}$ through the anionexchange process. These driving forces facilitate the attraction of anionic $\mathrm{CdI}_{4}^{2-}$ onto the modified silica gel surface, resulting in a favorable adsorption efficiency. For the environmental samples studied, pH 6.0 was selected in this work.

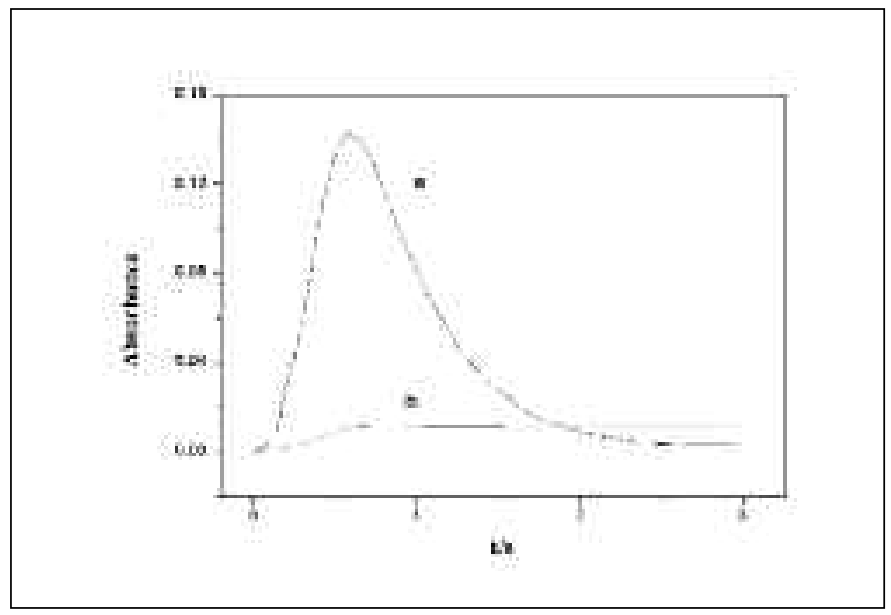

Fig. 1. Atomic absorption peaks of cadmium and the blank atomization at $1800^{\circ} \mathrm{C}$. (a) Cd in $\mathrm{HNO}_{3}$ medium with an SPE step; (b) only deionized doubly distilled water (the blank of Cd aqueous solution) in $\mathrm{HNO}_{3}$ medium with an SPE step. Conditions: Cd(II), $100 \mathrm{ng} \mathrm{L}^{-1}$; $\mathrm{pH}, 6.0$; KI, $0.01 \mathrm{~mol} \mathrm{~L}^{-1}$; eluent, $2.0 \mathrm{~mol} \mathrm{~L}^{-1} \mathrm{HNO}_{3}$; eluent volume, $1.2 \mathrm{~mL}$; sample flow rate/ elution flow rate, $4.0 \mathrm{~mL} \mathrm{~min}^{-1}$.

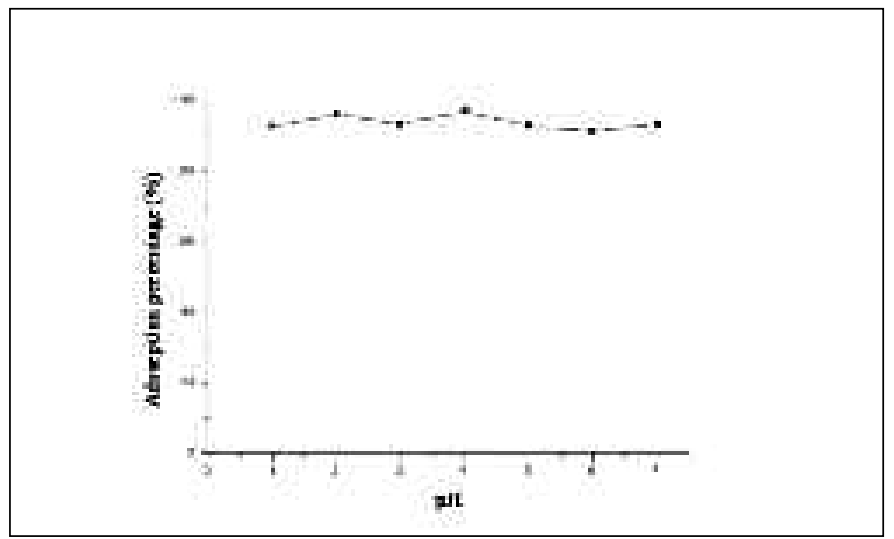

Fig. 2. Effect of $p H$ on the adsorption percentage of Cd(II). Conditions: Cd(II), $100 \mathrm{ng} \mathrm{L}^{-1}$; KI, $0.01 \mathrm{~mol} \mathrm{~L}^{-1}$; eluent, $2.0 \mathrm{~mol} \mathrm{~L}^{-1} \mathrm{HNO}_{3}$; eluent volume, $1.2 \mathrm{~mL}$;

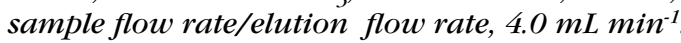

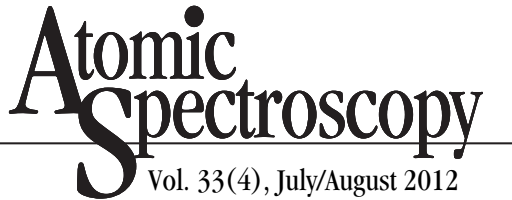

\section{Effect of KI Concentration}

The effect of KI concentration on the adsorption of cadmium was studied within the concentration range of $0-0.1 \mathrm{~mol} \mathrm{~L}^{-1}$. As can be seen from Figure 3 , in the absence of $\mathrm{I}^{-}$there is no adsorption of Cd(II) due to the electrostatic repulsion between the cationic Cd(II) and the positively charged AMSG surface, resulting in a very low adsorption percentage (\%) of the analyte. On the other hand, the addition of KI greatly affected the retention behavior of Cd(II) due to the formation of $\mathrm{CdI}_{4}^{2-}$ anions. The adsorption percentage of the analyte was accentuated by $\mathrm{KI}$ at concentrations up to about $0.0025 \mathrm{~mol} \mathrm{~L}^{-1}$. The quantitative adsorption achieved with this concentration remained constant up to $0.025 \mathrm{~mol} \mathrm{~L}^{-1}$. However, at higher concentrations the adsorption percentage of cadmium deteriorates probably due to the competitive reaction between the $\mathrm{CdI}_{4}{ }^{2-}$ and $\mathrm{I}^{-}$during the anionexchange process. Considering the competitive reaction with other metal ions in general, $0.01 \mathrm{~mol} \mathrm{~L}^{-1}$ KI was employed for further studies.

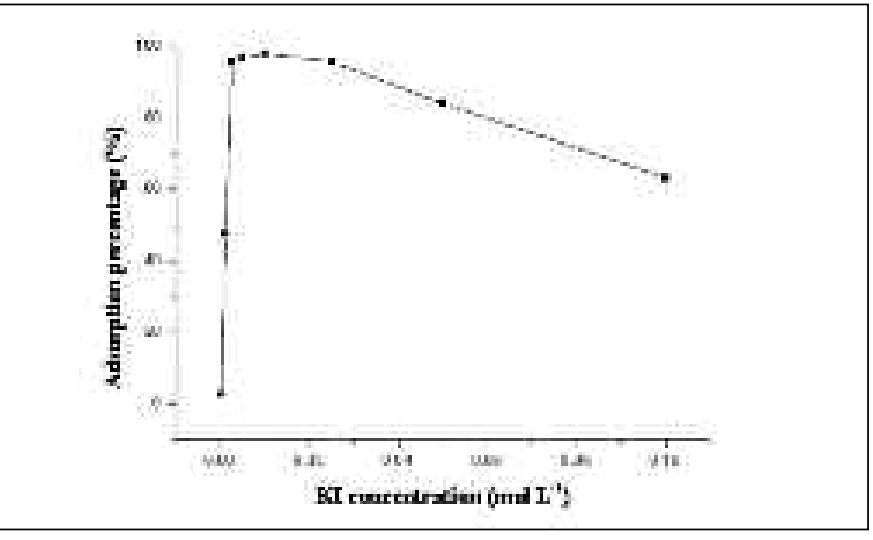

Fig. 3. Effect of KI concentration on the adsorption percentage of Cd(II). Conditions: Cd(II), $100 \mathrm{ng} \mathrm{L}^{-1} ; \mathrm{pH}, 6.0$; eluent, $2.0 \mathrm{~mol} \mathrm{~L}^{-1} \mathrm{HNO}_{3}$; eluent volume, $1.2 \mathrm{~mL}$; sample flow rate/ elution flow rate, $4.0 \mathrm{~mL} \mathrm{~min}^{-1}$. 


\section{Effect of Sample Flow Rate}

The sample flow rate should be optimized to achieve quantitative adsorption of the analyte while at the same time minimizing the time required for sample processing. The results showed that there is no obvious effect of sample flow rate on the adsorption percentage of $\mathrm{Cd}$ (II) with a flow rate varying from $0.5 \mathrm{~mL} \mathrm{~min}^{-1}$ to $4.0 \mathrm{~mL} \mathrm{~min}^{-1}$. This implies a fast kinetic reaction of Cd(II) with AMSG in the presence of $\mathrm{I}^{-}$. Therefore, a sample flow rate of $4.0 \mathrm{~mL} \mathrm{~min}^{-1}$ was used in order to improve the analytical efficiency in the subsequent experiments.

\section{Optimization of Elution Conditions}

\section{Effect of Type and Concentration of Eluent}

Choosing the most suitable eluent is very important to achieve quantitative and fast recovery of the analyte retained in the microcolumn. For the sake of acquiring the most suitable eluent, three kinds of different reagents $(\mathrm{HCl}$, $\mathrm{NH}_{4} \mathrm{NO}_{3}$, and $\mathrm{HNO}_{3}$ ) were tested. The experimental results demonstrated that quantitative recovery for cadmium was obtained only with $\mathrm{HNO}_{3}$.
With respect to stripping of the target analyte from the modified silica gel packed microcolumn, various concentrations $\left(0.1 \mathrm{~mol} \mathrm{~L}^{-1}-\right.$ $4.0 \mathrm{~mol} \mathrm{~L}^{-1}$ ) of $\mathrm{HNO}_{3}$ were studied for the desorption of retained $\mathrm{Cd}(\mathrm{II})$ in the microcolunm. Figure 4 shows the effect of $\mathrm{HNO}_{3}$ concentration on the recovery of the retained $\mathrm{Cd}(\mathrm{II})$. It can be seen that $1.0 \mathrm{~mol} \mathrm{~L}^{-1}-4.0 \mathrm{~mol} \mathrm{~L}^{-1}$ was sufficient for the quantitative recovery of Cd(II). In this work, $2.0 \mathrm{~mol} \mathrm{~L}^{-1}$ $\mathrm{HNO}_{3}$ was chosen.

\section{Effect of Eluent Volume}

An eluent volume as low as possible is preferred for a high enrichment factor. The influence of the elution volume on the recovery for triplicate determinations of cadmium at concentrations of $100 \mathrm{ng} \mathrm{L}^{-1}$ was investigated. Figure 5 shows that $1.2 \mathrm{~mL} \mathrm{HNO}_{3}$ (2.0 $\left.\mathrm{mol} \mathrm{mL}^{-1}\right)$ was sufficient for the quantitative elution of the analyte from the microcolumn.

\section{Effect of Eluent Flow Rate}

The effect of eluent flow rate was also investigated by keeping the eluent volume and eluent concentration at $1.2 \mathrm{~mL}$ and $2.0 \mathrm{~mol} \mathrm{~L}^{-1}$. The results showed that there was no significant variation of the recovery of Cd(II) when the eluent flow rate was in the $0.5-4.0 \mathrm{~mL} \mathrm{~min}^{-1}$

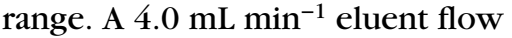
rate was selected in this work.

\section{Effect of Sample Volume}

In order to explore the possibility of enriching low concentrations of the analyte from large volumes, the effect of sample volume on the recovery of cadmium was investigated. For this purpose, sample solutions of $5,10,25,50,100,150$, 200 , and $250 \mathrm{~mL}$ containing $3.0 \mathrm{ng}$ Cd(II) were passed through the microcolumn using the above-mentioned general procedure. Figure 6 shows that Cd(II) was quantitatively recovered in all cases. Thus, the maximum sample volume of the developed method must be greater than $250 \mathrm{~mL}$. As described in the previous section, Cd(II) was quantitatively re-covered using $1.2 \mathrm{~mL}$ of $2.0 \mathrm{~mol} \mathrm{~L}^{-1} \mathrm{HNO}_{3}$. Thus it can be stated that a maximum theoretical enrichment factor of higher than 208 for Cd(II) was obtained in this work. Since ETAAS is a very sensitive technique, we did not make an effort to reach a very high enrichment factor. As a trade-off between the enrichment factor and analytical efficiency, the sample volume of $30.0 \mathrm{~mL}$ was used for the real sample analysis.

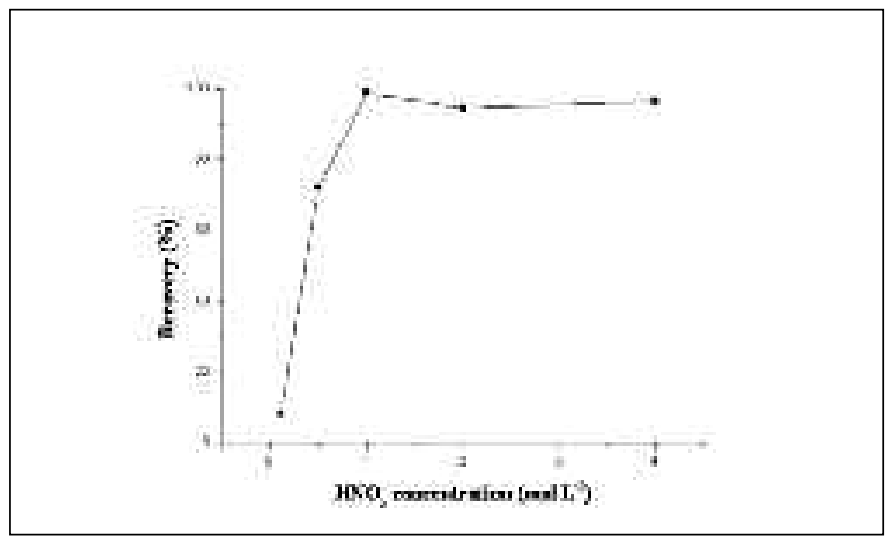

Fig. 4. Effect of $\mathrm{HNO}_{3}$ concentration on the recovery of Cd(II). Conditions: Cd(II), $100 \mathrm{ng} \mathrm{L}^{-1} ; \mathrm{pH}, 6.0 ; \mathrm{KI}, 0.01 \mathrm{~mol} \mathrm{~L}^{-1}$; eluent volume, $1.2 \mathrm{~mL}$; sample flow rate/elution flow rate, $4.0 \mathrm{~mL} \mathrm{~min}^{-1}$.

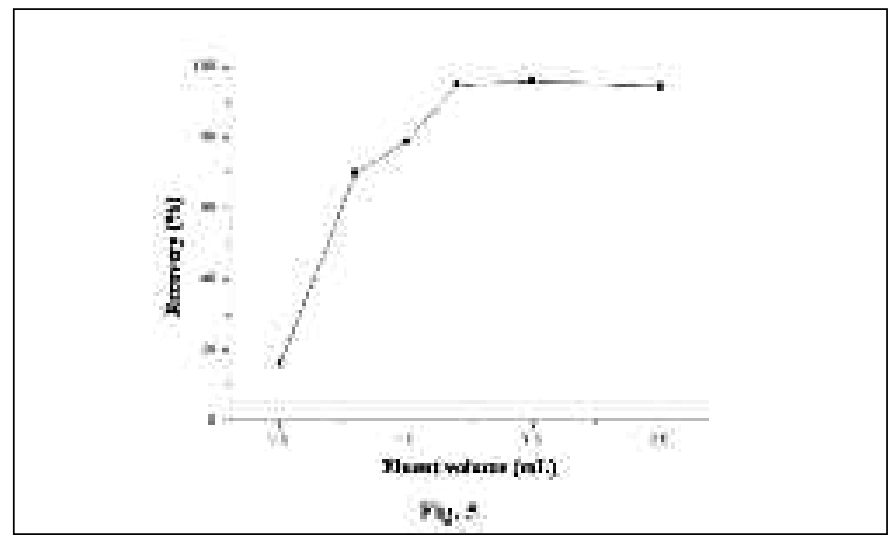

Fig. 5. Effect of eluent volume on the recovery of Cd(II). Conditions: Cd(II), $100 \mathrm{ng} \mathrm{L}^{-1} ; \mathrm{pH}, 6.0 ; \mathrm{KI}, 0.01 \mathrm{~mol} \mathrm{~L}^{-1}$; eluent, $2.0 \mathrm{~mol} \mathrm{L^{-1 }} \mathrm{HNO} 3$; sample flow rate/elution flow rate, $4.0 \mathrm{~mL} \mathrm{~min}^{-1}$. 


\section{Adsorption Capacity and Regeneration}

The adsorption capacity is an important factor in evaluating the property of the adsorption material, because it determines the amount of modified silica gel required to quantitatively concentrate cadmium from a given solution. The capacity study used was based on the method recommended by Pu et al. (30). The adsorption capacity of AMSG was found to be $6.5 \mathrm{mg} \mathrm{g}^{-1}$ for cadmium. It should be noted that the capacity value obtained in this work is much higher than the values reported in the literature, i.e., $0.5 \mathrm{mg} \mathrm{g}^{-1}$ for $\mathrm{Cd}$ (II) in modified clinoptilolite zeolite (31) and only about $0.002 \mathrm{mg} \mathrm{g}^{-1}$ for Cd(II) in 2-mercaptobenzo-thiazole modified sulfur powder sorbent (32); though it is lower than the capacity value of $12.4 \mathrm{mg} \mathrm{g}^{-1}$ for $\mathrm{Cd}$ (II) in XAD-761 resin (1).

Regeneration is one of the key factors in evaluating the performance of the adsorption material. The adsorbent material used in this work was stable with a long column lifetime and enabled more than 20 loading and elution cycles to be performed without loss of analytical performance. Our results indicate that AMSG is a suit- able substance for ultra-trace cadmium extraction and effective matrix separation.

\section{Effects of Coexisting Ions}

Alkali metals, alkaline earth metals, heavy metals and anions, which exist as the most common matrix constituents in seawater, were examined. In these experiments, solutions containing $100 \mathrm{ng} \mathrm{L}^{-1}$ of Cd(II), and the added coexisting ions, were studied according to the proposed procedure. The tolerance limit of coexisting ions, which gave

TABLE II

Tolerance Limit of Coexisting Ions for the Determination of $100 \mathrm{ng} \mathrm{L}^{-1} \mathrm{Cd}(\mathrm{II})$

\begin{tabular}{lc}
\hline $\begin{array}{c}\text { Coexisting } \\
\text { Ions }\end{array}$ & $\begin{array}{c}\text { Tolerance } \\
\text { Limit }\left(\mathrm{mg} \mathrm{L}^{-1}\right)\end{array}$ \\
\hline $\mathrm{Na}^{+}$ & 20,000 \\
$\mathrm{~K}^{+}$ & 10,000 \\
$\mathrm{Mg}^{2+}$ & 5000 \\
$\mathrm{Ca}^{2+}$ & 2000 \\
$\mathrm{Zn}^{2+}$ & 1000 \\
$\mathrm{Al}^{3+}$ & 100 \\
$\mathrm{Cu}^{2+}$ & 10 \\
$\mathrm{~Pb}^{2+}$ & 8 \\
$\mathrm{Fe}^{3+}$ & 1 \\
$\mathrm{Cl}^{-}$ & 30,000 \\
$\mathrm{SO}_{4}{ }^{2-}$ & 10,000 \\
\hline
\end{tabular}

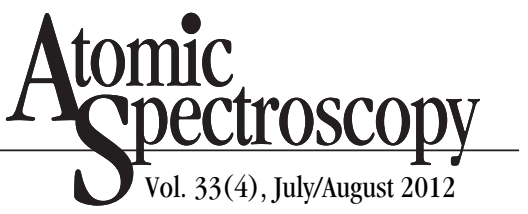

less than a $10 \%$ error for the determination of Cd(II), was evaluated and the results are listed in Table II. As can be seen, all tolerance limit values of the coexisting ions commonly found in seawater were higher than those typically found in real seawater. These results confirm that the developed method is appliable for the determination of trace cadmium in high-salinity environmental samples.

\section{Analytical Performance}

A calibration graph was obtained using the general procedure for different concentrations of cadmium under the optimal experimental conditions described above. A good linear relationship was achieved in the range of $20-500 \mathrm{ng} \mathrm{L}^{-1}$ in the initial solution with a correlation coefficient of 0.9991 . The result is presented in Figure 7 as calibration curve.

The limit of detection (LOD, based on three times the standard deviation of the blanks by 10 replicates) was $5.1 \mathrm{ng} \mathrm{L}^{-1}$ with an enrichment factor of 23.8 for a $30.0-\mathrm{mL}$ sample consumption. Better LOD can be achieved with a much larger volume. The relative standard deviation (RSD) for 10 replicate determinations of $100 \mathrm{ng} \mathrm{L}^{-1}$ of $\mathrm{Cd}(\mathrm{II})$ was

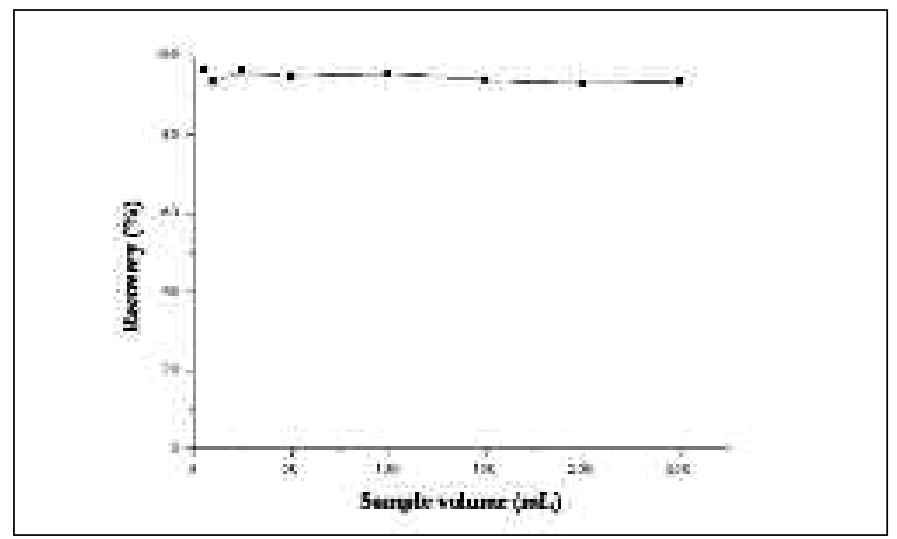

Fig. 6. Effect of sample volume on the recovery of Cd(II). Conditions: Cd(II), $3.0 \mathrm{ng}$; $\mathrm{pH}, 6.0$; KI, $0.01 \mathrm{~mol} \mathrm{~L}^{-1}$; eluent, $2.0 \mathrm{~mol} \mathrm{~L}^{-1} \mathrm{HNO}_{3}$; eluent volume, $1.2 \mathrm{~mL}$; sample flow

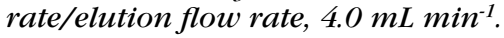

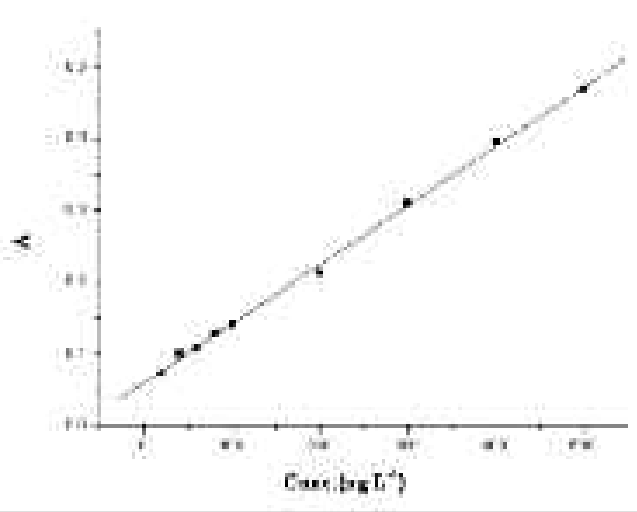

Fig. 7. Calibration curve. Conditions: Cd(II), 20, 40, 60, 80, 100, 200, 300, 400, $500 \mathrm{ng} \mathrm{L}^{-1} ; \mathrm{pH}, 6.0$; KI, $0.01 \mathrm{~mol} \mathrm{~L}^{-1}$; eluent, $2.0 \mathrm{~mol} \mathrm{~L}^{-1} \mathrm{HNO}_{3}$; eluent volume, $1.2 \mathrm{~mL}$; sample flow

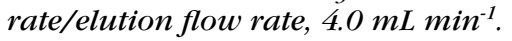


$2.3 \%$. A comparison of the analytical performance (including LOD, sampling frequency, sample preparation, and cost) obtained by this method with the EPA methods for the determination of cadmium is shown in Table III. It can be seen that (a) the LOD of the proposed method is much lower than that obtained by EPA Method 200.13 (33), and it is higher than that obtained by EPA Method 1640 (34); (b) the sampling frequency was better than that reported in the referenced literature $(33,34)$; (c) the cost of the developed method is comparable with EPA Method 200.13 and much lower than EPA Method 1640.

\section{Validation and Application}

For real sample analysis, the calibration curves of the standard series for Cd(II) were subjected to the same extraction procedure. To validate the method, the proposed method was applied to the analysis of $\mathrm{Cd}$ in seawater reference material GBW(E) 080040, and the determined value for Cd was obtained after subtracting the blank value. The concentration of cadmium was found to be $0.97 \pm 0.04 \mathrm{ng} \mathrm{mL}^{-1}$, which is commensurate with the certified value of $1.02 \pm 0.06 \mathrm{ng} \mathrm{mL}^{-1}$.

The developed method was also successfully applied to the determination of ultra-trace cadmium in four real seawater samples (Dalian, Beihai, Qingdao, and Xiamen, P.R. China). In order to examine the reliability and accuracy of the method, recovery experiments were carried out for these seawater samples by spiking them with two standard solutions of cadmium before applying the SPE procedure. Table IV shows the analytical results along with the recoveries for Cd in the various seawater samples. As can be seen, the concentrations of Cd(II) are in the range of 82.6-181.7 $\mathrm{ng} \mathrm{L}^{-1}$, and the recoveries for the target analyte ranged

Table III

Comparison of the Performance Found in the EPA Methods for the Determination of $\mathrm{Cd}$

\begin{tabular}{lccccc}
\hline $\begin{array}{l}\text { Analytical } \\
\text { Approach }\end{array}$ & $\begin{array}{c}\text { LOD } \\
\left(\mathrm{ng} \mathrm{L}^{-1}\right)\end{array}$ & $\begin{array}{c}\text { Sample } \\
\text { Preparation }\end{array}$ & $\begin{array}{c}\text { Sampling } \\
\text { Frequency }\left(\mathrm{h}^{-1}\right)\end{array}$ & Cost & Ref. \\
\hline ETAAS & 5.1 & SPE & 7 & + & This \\
& & & & + & work \\
EPA Method 200.13 & 16 & SPE & 4 & ++ & $(34)$ \\
EPA Method 1640 & 2.4 & SPE & 1 & +
\end{tabular}

"+" means "normal".

"++" means "expensive".

TABLE IV

Analytical Data of Cd Determined in Seawater Samples (mean $\pm S D, n=3)$

\begin{tabular}{lcrr}
\hline Sample & $\begin{array}{c}\text { Added } \\
\left(\mathrm{ng} \mathrm{L}^{-1}\right)\end{array}$ & $\begin{array}{c}\text { Determined } \\
\left(\mathrm{ng} \mathrm{L}^{-1}\right)\end{array}$ & $\begin{array}{c}\text { Recovery } \\
(\%)\end{array}$ \\
\hline Dalian Seawater & 0 & $92.0 \pm 1.8$ & - \\
& 100 & $185.7 \pm 6.9$ & 96.7 \\
Beihai Seawater & 200 & $281.3 \pm 9.2$ & 96.3 \\
& 0 & $82.6 \pm 2.3$ & - \\
Qingdao Seawater & 100 & $191.5 \pm 7.6$ & 104.9 \\
& 200 & $275.3 \pm 10.2$ & 97.4 \\
& 0 & $181.7 \pm 4.7$ & - \\
Xiamen Seawater & 100 & $269.4 \pm 8.5$ & 95.6 \\
& 200 & $407.8 \pm 14.2$ & 106.8 \\
& 0 & $123.2 \pm 4.1$ & - \\
& 100 & $213.9 \pm 9.2$ & 95.8 \\
& 200 & $338.1 \pm 7.6$ & 104.6 \\
\hline
\end{tabular}

from 95.6-106.8\%. These values show that the proposed method can be applied for the separation/ preconcentration of the target analyte.

\section{CONCLUSION}

Silica gel modified with Aliquat336 has been introduced as a novel adsorbent for the preconcentration of cadmium. The anion exchange nature of the Aliquat-336 modified silica gel hybrid, in addition to its positively charged surface, facilitate the retention of the $\mathrm{Cd}(\mathrm{II})$ in the presence of $\mathrm{I}^{-}$. In addition, the retained $\mathrm{Cd}$ (II) can readily be recovered from the surface of the modified silica gel by $\mathrm{HNO}_{3}$.
A solid phase extraction (SPE) approach for the selective separation and preconcentration of cadmium was developed using a conical pipet tip $(200 \mu \mathrm{L}$, inexpensive and easy to obtain) as the microcolumn packed with the modified silica gel particles. The method is simple, accurate, economical, and can be applied for the determination of cadmium in high-salinity environmental samples. Moreover, further improvement in the limit of detection (LOD) is feasible by preconcentration of larger amounts of sample solution. This procedure can also be adapted for rugged and routine use by contract laboratories analyzing water samples. 


\section{ACKNOWLEDGMENT}

Financial support from the National Natural Science Foundation of P.R. China (No. 41003015), the Natural Science Foundation of the Education Department of Henan Province (No. 2011B150010), and the Natural Science Foundation of Henan Polytechnic University (No. B2008-26 and YB016) is gratefully acknowledged.

Received February 16, 2012.

\section{REFERENCES}

1. H. Ciftci, Desalination 263, 18 (2010).

2. A.A. Ensafi and A.R. Ghaderi, J. Hazard. Mater. 148, 319 (2007).

3. E. Vassileva and M. Hoenig, Anal. Chim. Acta 701, 37 (2011).

4. F. Zheng and B. Hu, Talanta 85, 1166 (2011).

5. J. C. Moss, C.J. Hardaway, J.C. Richert, and J. Sneddon, Microchem. J. 95, 5 (2010).

6. E.L. Silva, P.D. Roldan, and M.F. Gine, J. Hazard. Mater. 171, 1133 (2009).

7. E.V. Oral, I. Dolak, H. Temel, and B. Ziyadanogullari, J. Hazard.Mater. 186, 724 (2011).

8. S. Mahpishanian and F. Shemirani, Talanta 82, 471 (2010).

9. S.Q. Li, S. Cai, W. Hu, H. Chen, and H.L. Liu, Spectrochim. Acta Part B 64, 666 (2009).

10. E.M. Martinis, R.A. Olsina, J.C. Altamirano, and R.G. Wuilloud, Anal. Chim. Acta 628, 41 (2008).

11. H.M. Jiang and B. Hu, Microchim. Acta 161, 101 (2008).

12. D. Citak, M. Tuzen, and M. Soylak, Food Chem. Toxicol. 47, 2302 (2009).
13. T. Oymak, S. Tokalioglu, V. Yilmaz, S. Kartal, and D. Aydin, Food Chem. 113, 1314 (2009).

14. G.D. Rodrigues, M.D.H. da Silva, L.H.M. da Silva, F.J. Paggioli, L.A. Minim, and J.S.D. Coimbra, Sep. Purif. Technol. 62, 687 (2008).

15. H.C. Rezende, C.C. Nascentes, and N.M.M. Coelho, Microchem. J. 97, 118 (2011).

16. C.K. Ahn, Y.M. Kim, S.H. Woo, and J.M. Park, Hydrometallurgy 99, 209 (2009)

17. H. Parham, N. Pourreza, and N. Rahbar, J. Hazard.Mater. 163, 588 (2009).

18. G.Q. Xiang, Y. Huang, and Y.F. Luo, Microchim. Acta 165, 237 (2009).

19. S. Tokalioglu, V. Yilmaz, and S. Kartal, Environ. Monit. Assess. 152, 369 (2009).

20. Q.X. Zhou, X.N. Zhao, and J.P. Xiao, Talanta 77, 1774 (2009).

21. B. Parodi, M. Savio, L.D. Martinez, R.A. Gil, and P. Smichowski, Microchem. J. 98, 225 (2011).

22. W. Ngeontae, W. Aeungmaitrepirom, and $\mathrm{T}$. Tuntulani, Talanta 71, 1075 (2007).

23. Y. Tian, P. Yin, R.J. Qu, C.H. Wang, H.G. Zheng, and Z.X. Yu, Chem. Eng. J. 162, 573 (2010).

24. X. L. Chai, X.J. Chang, Z. Hu, Q. He, Z.F. Tu, and Z.H. Li, Talanta 82, 1791 (2010).

25. A.S. Pereira, G. Ferreira, L. Caetano, M.A.U. Martines, P.M. Padilha, A. Santos, and G.R. Castro, J. Hazard. Mater. 175, 399 (2010).

26. W. Aeungmaitrepirom, W. Ngeontae, and T. Tuntulani, Anal. Sci. 25, 1477 (2009).

27. S.S. Bozkurt and M. Merdivan, Environ. Monit. Assess. 158, 15 (2009).

28. S. Sadeghi and E. Sheikhzadeh, J. Hazard. Mater. 163, 861 (2009).

29. N.N. Meeravali and S.J. Jiang, Talanta 80, 173 (2009).
30. X.L. Pu, B. Hu, Z.C. Jiang, and C.Z. Huang, Analyst 130, 1175 (2005).

31. A. Malekpour, S. Hajialigol, and M.A. Taher, J. Hazard. Mater. 172, 229 (2009).

32. N. Pourreza and K. Ghanemi, J. Hazard. Mater. 178, 566 (2010).

33. U.S. EPA method 200. 13, Cincinnati, OH, USA (1992).

34. U.S. EPA Method 1640, Washington, DC, USA (1997). 